\title{
EFEITO DO TIPO DE EMBALAGEM E DO TEMPO DE ARMAZENAMENTO NAS QUALIDADES FÍSICO-QUÍMICAS DE CENOURA MINIMAMENTE PROCESSADA
}

\section{EFFECT OF PACKAGING TYPE AND STORAGE TIME ON PHYSICO- CHEMICAL QUALITIES OF MINIMALLY PROCESSED CARROTS}

\author{
A. L. S. MIRANDA ${ }^{1}$, D. R. P. MARQUES ${ }^{1}$, L. P. PASSOS $^{1}$, I. R. N. OLIVEIRA ${ }^{1}$ \\ ${ }^{1}$ Instituto de Ciências Agrárias. Universidade Federal de Viçosa - Campus Rio Paranaíba \\ E-mail: ana.miranda4@ufv.br
}

article info

Article history:

Received 12 May 2017

Accepted 3 August 2017

Available online 20 September 2017
PALAVRAS-CHAVE: Baby carrot; Cenourete; Catetinho; Daucus carota L. KEYWORDS: Baby carrot; Cenourete; Daucus carota L.

RESUMO: Os minimamente processados são oferecidos aos consumidores de forma a trazer vantagens, pois reduz o tempo de preparação dos alimentos, é uma oferta de produto saudável agregado a qualidade e vem crescendo nos últimos anos em consequência do estilo de vida dos consumidores que tem sofrido transformações. As cenouras foram processadas para obtenção de mini-cenouras, assim este trabalho, teve como objetivo avaliar o efeito da embalagem sob armazenamento de cenoura minimamente processadas. Os produtos foram armazenados nas diferentes embalagens (bandeja de poliestireno com cobertura de policloreto de polivinila (PVC) ou potes de polipropeno) e armazenados sob refrigeração (7oC) por 10 dias. As análises de pH, acidez, sólidos solúveis totais (SST), umidade, perda de massa e carotenoides totais foram realizadas durante o armazenamento. Os resultados mostraram que a acidez inicial foi maior quando comparada com os demais dias e o pH teve uma diminuição ao longo da armazenagem, para ambas as embalagens. A umidade manteve-se próxima a inicial, não tendo diferença entre as embalagens e o tempo. A perda de massa foi similar nas embalagens utilizadas. Os teores de carotenoides e sólidos solúveis obtiveram interação significativa entre o tempo de armazenamento e as embalagens, onde os teores foram maiores ao longo do tempo na embalagem com filme de PVC. Concluiu-se que a embalagem mais apropriada para mini-cenouras foi a bandeja de poliestireno com filme PVC, pois aumentou o teor de carotenoides e sólidos solúveis totais durante o armazenamento e manteve a umidade do produto.

\footnotetext{
ABSTRACT: Minimally processed foods are offered to consumers in order to bring advantages, since it reduces the preparation time of the food, it is a healthy product offering added to the quality and it has been growing in the last years as a result of the lifestyle of the consumers that have undergone transformations. The carrots were processed to obtain mini-carrots, so this work had as objective to evaluate the effect of the packaging under carrot storage minimally processed. The products were stored in the different containers (polystyrene tray with polyvinyl chloride (PVC) cover or polypropene pots) and stored under refrigeration (7oC) for 10 days. Analyzes of $\mathrm{pH}$, acidity, total soluble solids (TSS), moisture, mass loss and total carotenoids were performed during storage. The results showed that the initial acidity was higher when compared to the other days and the $\mathrm{pH}$ had a decrease throughout the storage, for both packages. The humidity remained close to the initial one, having no difference between the packages and the time. The loss of mass was similar in the packages used. The levels of carotenoids and soluble solids obtained a significant interaction between the storage time and the packages, where the contents were higher over time in the PVC film packaging. It was concluded that the most appropriate packaging for mini carrots was the polystyrene tray with PVC film, as it
} 


\section{The Journal of Engineering and Exact Sciences - \\ JCEC \\ ISSN: 2527-1075}

increased the content of carotenoids and total soluble solids during storage and maintained the moisture of the product.

\section{INTRODUÇÃ̃o}

Produtos minimamente processados são frutas ou hortaliças que tenham sofrido alterações físicas, e preservem seu estado fresco. A matéria-prima utilizada é selecionada, sanificada, descascada e cortada, tendo como resultado um produto aproveitável que é, posteriormente, embalado, oferecendo aos consumidores frescor, conveniência e qualidade nutricional (IFPA, 2007). No Brasil, foi a partir dos anos 90, que começou de forma consistente e sistematizada a busca e o desenvolvimento de tecnologia para o processamento mínimo de frutas e hortaliças (MORETTI, 2007).

A cenoura (Daucus carota L.) está entre as culturas que apresenta grandes chances de deformações, por conta da elevada ocorrência de bifurcações nas raízes, podendo chegar a $30 \%$ da produção (SABIO et al., 2015). Esses produtos fora do padrão acarreta em perdas econômicas, e uma alternativa para agregar valor seria o beneficiamento deste produto. Entre as formas mais populares de cenoura minimamente processadas estão a ralada, em fatias, cubos ou palitos e mini-cenoura (baby carrot) (MORETTI, 2007).

O presente trabalho objetivou avaliar o efeito da embalagem sobre as características físico-químicas de cenouras minimamente processadas (cenourete e catetinho) armazenadas por 10 dias sob refrigeração.

\section{MATERIAL E MÉTODOS}

As cenouras (Daucus carota L.) foram obtidas no comércio de Rio Paranaíba - MG e encaminhadas ao CVT (Centro Vocacional Tecnológico), situado em Rio Paranaíba, Minas Gerais, para o procedimento de beneficiamento. Inicialmente as hortaliças foram lavadas e sanitizadas em solução de hipoclorito de sódio $(100 \mathrm{ppm} / 15 \mathrm{~min})$, sendo posteriormente enxaguadas com água e em solução de hipoclorito de sódio (5ppm). As cenouras foram descascadas com auxílio de descascador manual e as partes impróprias foram removidas com facas de aço inoxidável.

As cenouras foram cortadas e posteriormente colocadas no tambor giratório (Metvisa, DBCA 6), para obtenção das mini-cenoura (baby carrot). Os produtos foram novamente higienizados em solução de hipoclorito de sódio (20ppm/10min). Após enxague, a água dos vegetais foi drenada. $\mathrm{O}$ produto foi pesado e acondicionado em duas diferentes embalagens: bandeja de poliestireno com filme de policloreto de polivinila (PVC) e potes de polipropeno.

As amostras foram armazenadas sob refrigeração $\left(7^{\circ} \mathrm{C}\right)$, durante 10 dias, sendo as análises realizadas no Laboratório de análise de alimentos, na Universidade Federal de Viçosa - Campus de Rio Paranaíba.

Foram realizadas análises físico-químicas de $\mathrm{pH}$, sólidos solúveis totais ( ${ }^{\circ} \mathrm{Brix}$ ), acidez titulável, umidade (IAL, 2008). O teor de carotenoides foi determinado segundo metodologia descrita por Rodriguez-Amaya (2001). Para todas as análises, as amostras de cenoura foram trituradas em processador de alimentos para homogeneização. 


\section{The Journal of Engineering and Exact Sciences - \\ JCEC \\ ISSN: 2527-1075}

Um mesmo grupo de amostras foi utilizado para as pesagens consecutivas do início ao fim do período de estocagem, para verificação da perda de massa durante o armazenamento.

O experimento foi conduzido em delineamento inteiramente casualizado (DIC) em arranjo fatorial 2x6 (fator 1: embalagem em 2 níveis; e fator 2: tempo em 6 níveis), com três repetições. Os resultados foram avaliados por meio de análise de variância (ANOVA) e regressão. Os modelos foram escolhidos com base na significância dos coeficientes de regressão, utilizando-se o teste t, no nível de 5\% de probabilidade. Quando aplicável, as médias foram comparadas utilizando-se o teste t, adotando-se o nível de 5\% de probabilidade. Todas as análises estatísticas foram conduzidas utilizando-se o programa estatístico $\mathrm{R}$ (The $\mathrm{R}$ Project for Statistical Computing), versão 3.3.0.

\section{RESULTADOS E DISCUSSÃO}

Analisando a ANOVA foi observado que não houve interação significativa ( $p>0,05$ ) entre os dois fatores analisados (tempo e embalagem) para as análises $\mathrm{pH}$ e acidez, o que pode ser observado na Figura 1.
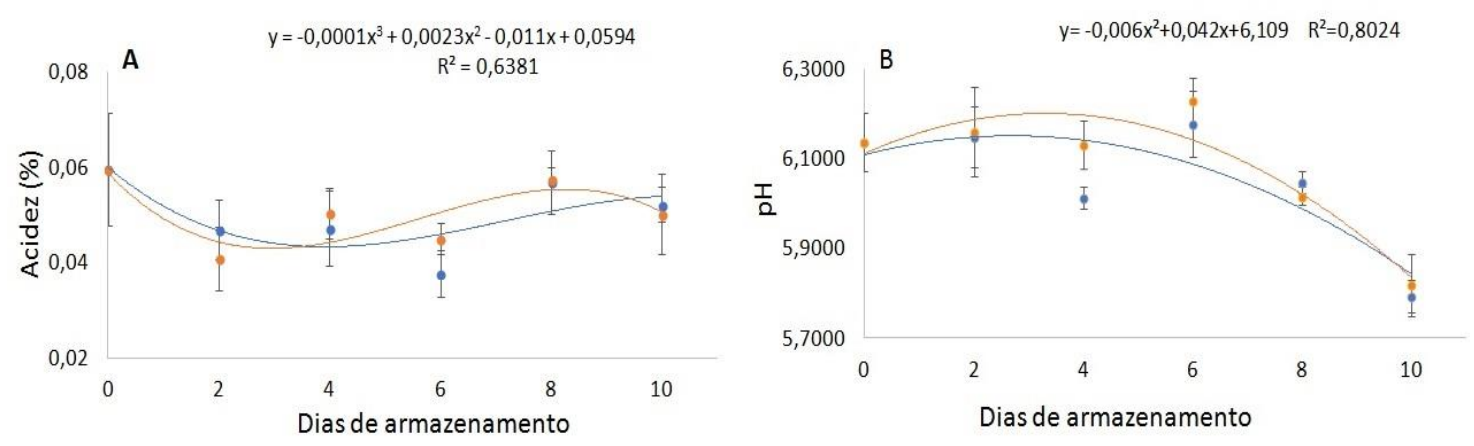

Figura 1 - Relação de acidez (A) e pH (B) entre o período de armazenamento de cenoura minimamente processada com embalagem em pote de polipropeno $(\bullet)$ e filme de $\operatorname{PVC}\left({ }^{\circ}\right)$.

A variação da acidez (Figura 1A) não foi influenciada pela embalagem $(p>0,05)$ e ao longo do tempo apresentou uma variação explicada por um polinômio de $3^{\circ}$ grau, onde a acidez inicial foi maior.

Ao longo do armazenamento houve diminuição dos valores de $\mathrm{pH}$ (Figura 1B), o que pode indicar um aumento de íons $\mathrm{H}+$ provenientes da produção de ácidos orgânicos por microrganismos. Baardseth et al. (1995), em estudo com cenouras cortadas em "chips", encontrou também uma redução nos valores de $\mathrm{pH}$.

A análise estatística mostrou interação significativa $(\mathrm{p}<0,05)$ do tempo e embalagens no teor de carotenoides e no teor de sólidos solúveis totais ( $\left.{ }^{\circ} \mathrm{Brix}\right)$, demonstrando que houve diferença significativa entre os dias e as embalagens utilizadas (Figura 2). 


\section{The Journal of Engineering and Exact Sciences - \\ JCEC \\ ISSN: 2527-1075}
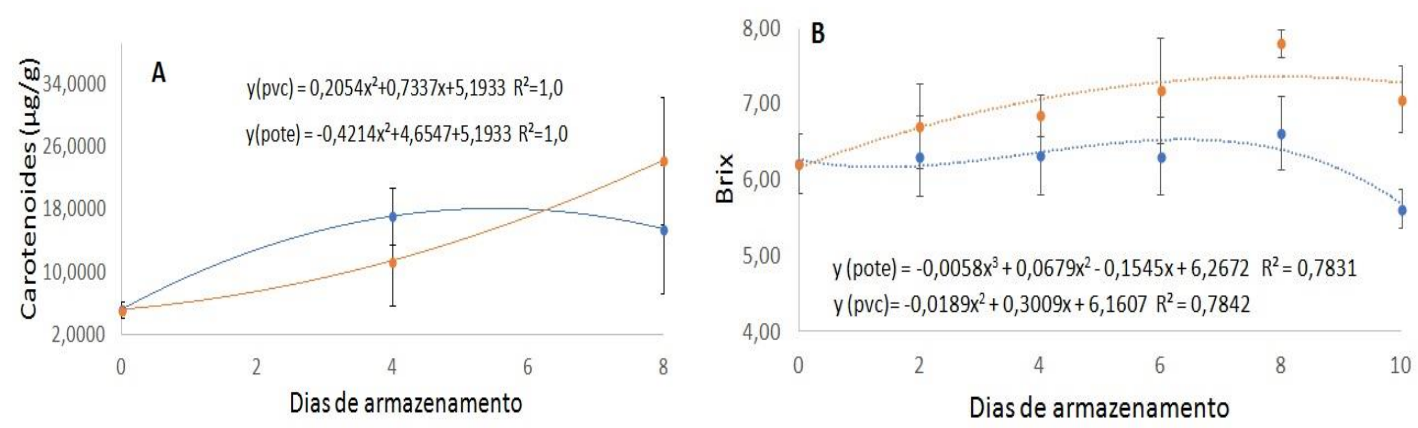

Figura 2 - Relação de carotenoides (A) e sólidos solúveis totais (B) entre o período de armazenamento de cenoura minimamente processada com embalagem em pote de polipropeno $(\bullet)$ e filme de $\mathrm{PVC}\left({ }^{\bullet}\right)$.

A variação do teor de carotenoides ao longo do tempo, para cada embalagem, pode ser explicada pelas equações apresentadas na Figura 2A. Observa-se que houve um aumento até o $6^{\circ}$ dia no teor de carotenoides totais para ambas as embalagens, porém para os produtos armazenados em pote de polipropileno houve uma diminuição após esse dia, enquanto que para os produtos armazenados em filme de PVC houve aumento no teor de carotenoides. Isto demonstra que pode haver variação na retenção de carotenoides totais em função das características do filme plástico utilizado. Segundo Carlin et al. (1990b), cenoura embalada em filme menos permeável ao oxigênio não mostrou alteração nos teores de carotenoides, já para o filme mais permeável ao oxigênio apresentou uma redução de $25 \%$ do teor inicial, após 12 dias de armazenamento.

Houve uma redução do teor de sólidos solúveis totais ( ${ }^{\circ}$ Brix), para os produtos embalados em pote de polipropileno ao longo dos dias (Figura 2B). Segundo Fan (1992), durante o armazenamento pode ocorrer quedas no teor de Brix devido ao consumo dos substratos no metabolismo respiratório dos frutos. O acréscimo no teor de sólidos solúveis foi evidenciado nos produtos embalados filme de PVC. Sasaki et al. (2006) avaliaram abóbora (Cucurbita moschata Duch), em diferentes cortes, observando que o corte em meia rodela teve um pequeno acréscimo no teor de sólidos solúveis, isso pode estar associado à perda de água durante o armazenamento. Chitarra e Chitarra (2005) afirmam que os teores de sólidos solúveis aumentam com o processo de amadurecimento do fruto, por biossíntese ou por degradação de polissacarídeos (aumento do teor de açucares simples) ou pela perda de água.

As embalagens não apresentaram influência significativa para perda de massa e umidade ao final da armazenagem, apresentando médias estatisticamente iguais (Tabela 1).

A umidade das cenouras minimamente processadas manteve-se próxima da inicial $(89,80 \pm 0,58)$ até o fim do experimento, não havendo diferença significativa ao longo do tempo de armazenamento (p>0,05). A umidade das amostras está similar a TACO (2011), sendo considerada característica do produto in natura. 


\section{The Journal of Engineering and Exact Sciences - \\ JCEC \\ ISSN: 2527-1075}

Tabela 1 - Perda de massa (\%) e umidade (\%) para as diferentes embalagens no final dos 10 dias de armazenamento refrigerado $\left(7^{\circ} \mathrm{C}\right)$

\begin{tabular}{ccc}
\hline Parâmetro & \multicolumn{2}{c}{ Embalagem } \\
\cline { 2 - 3 } & Pote & PVC \\
\hline Perda de massa $(\%)$ & $24,24 \pm 2,10^{\mathrm{ns}}$ & $24,79 \pm 4,86^{\mathrm{ns}}$ \\
\hline Umidade $(\%)$ & $87,66 \pm 11,90^{\mathrm{ns}}$ & $87,80 \pm 7,88^{\mathrm{ns}}$ \\
\hline
\end{tabular}

ns: diferença não significativa, na linha, pelo teste t.

A umidade e a perda de água são importantes para avaliar a vida útil do produto minimamente processado, podendo ser uma das causas de deterioração desses produtos (KADER, 1986). Cenouras minimamente processadas com variação de umidade causa perda de turgidez, esbranquiçamento da superfície e deterioração microbiológica, porque a umidade contribui com acumulo de gotas condensadas na superfície e na embalagem do produto, permitindo que qualquer microrganismo presente se espalhe com facilidade para toda a embalagem (BRACKETT, 1994; DAY, 2001). As embalagens utilizadas não proporcionaram variação de umidade do produto, e estes efeitos adversos podem ter sido minimizados.

O principal fator responsável para perda de massa é a transpiração, que está intimamente ligada a respiração do produto vegetal. Este parâmetro reduz a vida útil de hortaliças e também sua qualidade. Quando o armazenamento é feito em condições de umidade relativa elevada e baixa temperatura essa perda de água é minimizada e assim diminui a deterioração dos atributos de qualidade (textura, valor nutritivo, etc.) (CHITARRA, CHITARRA, 2005).

\section{CONCLUSÕES}

É de grande importância o estudo da embalagem apropriada para cada tipo de alimento, levando em consideração a taxa respiratória, a quantidade de água do alimento e a temperatura de armazenamento, entre outros fatores que estão relacionados a vida útil e a segurança dos produtos minimamente processados. Para as cenouras processadas observou-se que a embalagem mais apropriada foi a que utilizou filme PVC, pois manteve elevado o teor de carotenoides e sólidos solúveis totais, e não afetou a umidade das cenouras processadas, porém não foi eficaz para reduzir a perda de massa do produto.

\section{REFERÊNCIAS}

BAARDSETH,P.; ROSENFELD, H. J.; SUNDT, T. W.; SKREDE, G.; LEA, P. \& SLINDE, E. Evaluation of carrot varieties for production of deep-fried carrot chips - I. Chemical aspects. Food Research International, v. 28, n. 3, p. 195-200, 1995.

BRACKETT, R. E. Microbiological spoilage and pathogens in minimally processed refrigerated fruits and vegetables. In: WILEY, R.C. Minimally processed refrigerated fruits and vegetables. New York: Chapman \& Hall, 1994. p. 269-312.

CARLIN, F.; NUGYEN-THE, C.; HILBERT, G.; CHAMBROY, Y. Modified atmosphere packaging of fresh "ready-to-use" grated carrots in polymeric films. Journal of Food Science, v. 55, n. 4, p. 1033-1038, 1990. 
CHITARRA, M. I. F.; CHITARRA, A. B. Pós-colheita de frutas e hortaliças: fisiologia e manuseio. 2. ed. Lavras: UFLA, 2005. 785 p.

DAY, B. P. F. Fresh prepared produce: GMP'for high oxygem MAP and non-sulphite dipping. Campden: Chorleywood Food Research Association Group, 2001. Guideline n. 31 .

FAN, X. Maturity and storage of "Fuji" apples. 1992. 201p. Dissertation (Master of Science in Horticulture) - Washington State University, 1992.

IAL. Instituto Adolfo Lutz. Métodos Físico-Químicos para Análise de Alimentos. 4.ed. São Paulo, SP: Instituto Adolfo Lutz, 2008. 1020p.

IFPA. Internacional freshcut produce association. 2007. Disponível em: $<$ http://www.freshcuts.org >. Acesso em: 19 mar. 2017.

KADER, A. A. Biochemical and physiological basis for effects of controlled and modifi ed atmospheres on fruits and vegetables. Food Technology, v. 40, n. 5, p. 99-104, 1986.

MORETTI, C. L. Processamento mínimo de minicenoura. Manual de processamento mínimo de frutas e hortaliças. Brasília, DF: Embrapa/ SEBRAE, 2007. p. 397-413.

RODRIGUEZ-AMAYA, D. A Guide to Carotenoids Analysis in Food. Washington: International Life Sciences Institute Press, 2001. 64p.

SABIO, R. P.; GARCIA, J. B.; DUARTE, E. N.; PACHECO, A. L. A. A vez dos feios. HF Brasil. Hortifruti/Cepea, 2015. p. 10-18.

SASAKI, F. F.; DEL AGUILA, J. S.; GALLO, C. R.; ORTEGA, E. M. M.; JACOMINO, A. P.; KLUGE R A. Alterações fisiológicas, qualitativas e microbiológicas durante o armazenamento de abóbora minimamente processada em diferentes tipos de corte. Horticultura Brasileira, Brasília, v. 24, n. 2, p. 170-174, 2006.

TACO. Tabela brasileira de composição de alimentos. 2011. 161p. 